\title{
UNDERSTANDING THE EXPECTATIONS OF YOUNG EMPLOYEES TOWARDS LEADERSHIP IN ORGANIZATIONS
}

Iza Gigauri, PhD in Business Administration, Associate Professor, School of Business, Computing and Social Sciences, St. Andrews Georgian University, Tbilisi, Georgia,

ORCID: https://orcid.org/0000-0001-6394-6416

\section{DOI: https://doi.org/10.31435/rsglobal_conf/25042021/7521}

\begin{abstract}
The presented research explores the expectations of young employees to leadership and reveals their attitude towards leaders in organizations. The study elaborates on leadership styles, traits, and behaviors the new generation anticipates from the leaders. Additionally, the research analyzes the similarities and differences of male and female leaders in young workers' views. The research was based on a quantitative approach, and a survey method was used to gather primary data in Georgia. The study results emphasize the preferences of young employees towards leaders, which can be used by organizations to develop leadership styles accordingly, and attract and retain employees as a consequence.
\end{abstract}

Keywords. Leadership, Employee, Job satisfaction, Male leaders, Female leaders, Georgia.

Introduction. Leadership is a widely discussed topic in theory and practice. Effective leaders contribute to organizational success and financial performance. Leaders are influencing employee wellbeing and job satisfaction, which in turn positively stimulate labor productivity.

Research on leadership in Georgia does not yet paint a clear picture of the leaders' skills, traits, behaviors as well as gender differences the young generation of employees prefers. This study has been carried out to examine the expectations and attitudes of young employees to leadership in organizations in Georgia. This paper elaborates on leadership differences in male and female leaders in young workers' views and analyzes the skills and behaviors successful leaders must possess.

In this research, two general research questions are considered. Firstly, what expectations have the new generation who is entering the job market towards leaders and organizational leadership? To address this question, we studied the traits, skills, and behaviors a leader is expected to have. Second, do the young employees consider the difference in gender of a leader? To address this question, we consider whether they prefer male or female leaders in their organizations.

In the next sections, the theoretical background is presented with a review of the relevant literature. Then, research methods are explained and study results are provided, following the discussion and conclusions. Finally, future studies in this field are also discussed.

Literature Review. Leadership is still an extensively debated topic with various definitions, approaches, views, and methods (Leitão et al., 2021), as it has direct and indirect results to organizations and employees.

Traditionally, a leadership description centers behaviors and traits of leaders (Donkor \& Sekyere, 2020). Bendell and Little (2015) define Leadership as a behavior to help people to achieve something significant, and the act of leadership involves an assumption about values and change theories. Individual traits, situational factors, and behavioral factors are equally important for a leader (Förster \& Duchek, 2017).

The researchers confirm that leadership behavior and skills determine the trust of followers, and leadership depends on characteristics of a leader such as honesty, courage, commitment, and integrity (Chankova \& Vasilev, 2020).

Furthermore, scholars argue that leadership styles influence organizational citizenship behavior, and while democratic leaders stimulate organizational citizenship behavior, autocratic leadership with its task-oriented nature cannot contribute to it (Malik et al., 2016).

The previous research has found out the relationship between innovation and performance, and that enhanced innovation increases performance (Leitão et al., 2021). 
Given that leaders support employees and create favorable conditions, they promote innovation in organizations by developing human capital (Leitão et al., 2021). Especially, transformational leaders contribute to innovativeness, as they are flexible, open-minded, with strategic thinking, they motivate people and explore new ideas, which results in improved team performance and business profit (Leitão et al., 2021). The studies confirm that a leader's engagement in transformational behavior decreases employee stress and burnout (Diebig et al., 2017).

Moreover, leaders have an effect on the reputation and trust of a firm, which in turn affects the recruitment effectiveness, job satisfaction of employees, organizational commitment, and financial performance of an organization (Sajfert et al., 2017).

Provided that leadership impacts a corporate culture that as a result influences a firm's performance, leaders with the appropriate style and behavior can shape organizations' success (Kusdi, 2020). Leaders ensure that employees or team members have the same values, views, and perspectives, which induces corporate performance (Kusdi, 2020).

Leaders need social skills to interact with group members, to deal with people with responsibility (Galli, 2021). Communication composed of listening and speaking is one of the essential elements of leadership (Galli, 2021). Leaders devote their working hours to with interacting their teams through new communication technologies (Galli, 2021). But employees prefer face-to-face communication to the Internet tools or mobile phones (Kulshreshtha \& Sharma, 2021).

Despite the favorable culture of men leaders and barriers, female leaders are rising in many countries, and organizations, as they are more collaborative, participative, and democratic in their leadership styles (Eagly, 2020).

Research Methods. The research was based on a quantitative approach, and a survey method was used to gather primary data in Georgia. The questionnaire included closed-ended questions such as dichotomous questions, multiple-choice questions, and 5-point Likert rating scale questions. The survey was conducted through the Internet. The questionnaire was distributed through Google Forms to the young people aged 18-25 years old, who have jobs and are entering the job market as new employees. In total, 84 young people participated in the survey. The results were analyzed through descriptive statistics in MS Excel and SPSS.

Research Results. The research found out the qualities and characteristics young employees expect from leaders (Figure 1). They prefer leaders who are ready to help (12\%), and are agreeable $(11 \%)$. Besides, they consider leaders to be a good example (11\%) and communicate effectively $(10 \%)$. Additionally, leaders should recognize the achievements of their employees $(11 \%)$, create corporate culture $(10 \%)$, and represent organizational vision and objectives (10\%). They also make decisions (9\%), set standards (8\%), and achieve results $(8 \%)$.

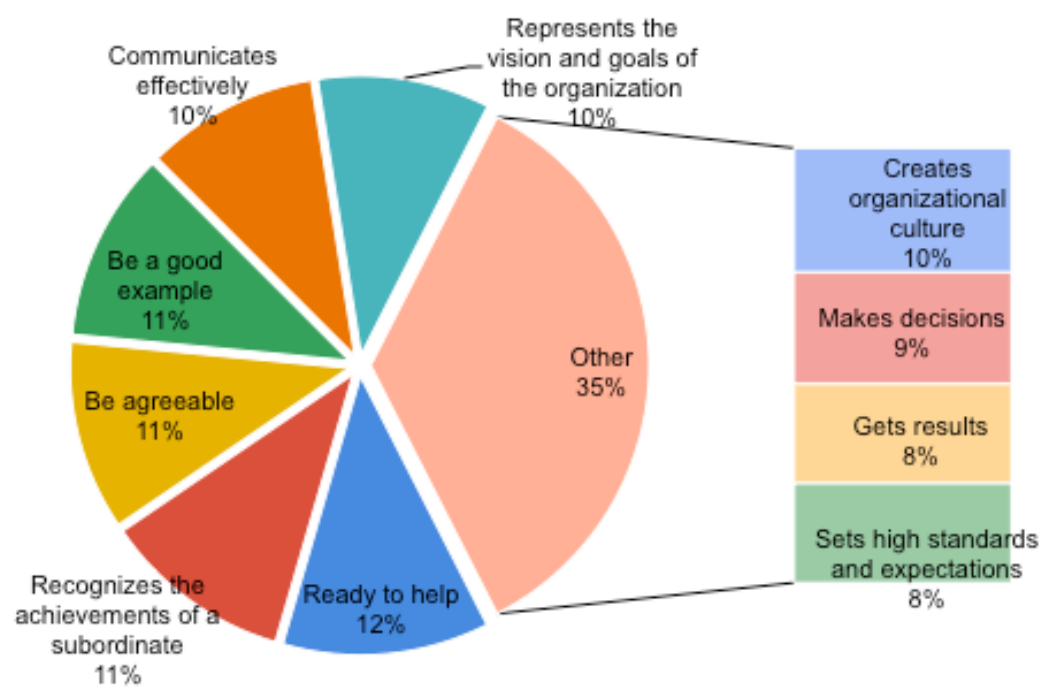

Fig. 1. What qualities and characteristics must a leader have in an organization? (Select all that apply). Note: The respondents could choose several answers from Multi-select Multiple Choice Questions. Multi-Select Multiple Choice Question, Does not add up to 100\% 
Moreover, the vast majority of survey participants $(n=71)$ believe that leaders should always support employees during job performance (Figure 2). None of them assume that leaders do not help workers, and only 12 of them think that leaders should sometimes assist employees.

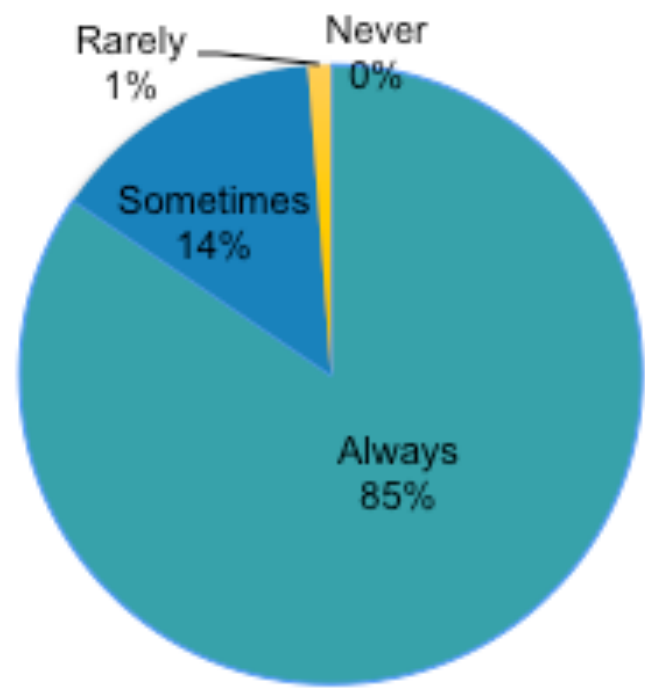

Fig. 2. How often, do you think, an employee should get help from a leader during the work process?

The young employees respondent to the statements concerning their attitude towards male and female leaders, their education, traits, effectiveness, and how they perceive themselves as leaders (Figure 3). The respondents agree and strongly agree that a leader's sex does not play any role and neither men nor women are better leaders. Instead, innate traits, leadership skills, and education are most important for successful leaders. In addition, the respondents agree with the statements that they are leaders by positions $(n=34)$, or they are still leaders in their organizations despite their official positions $(\mathrm{n}=29)$.

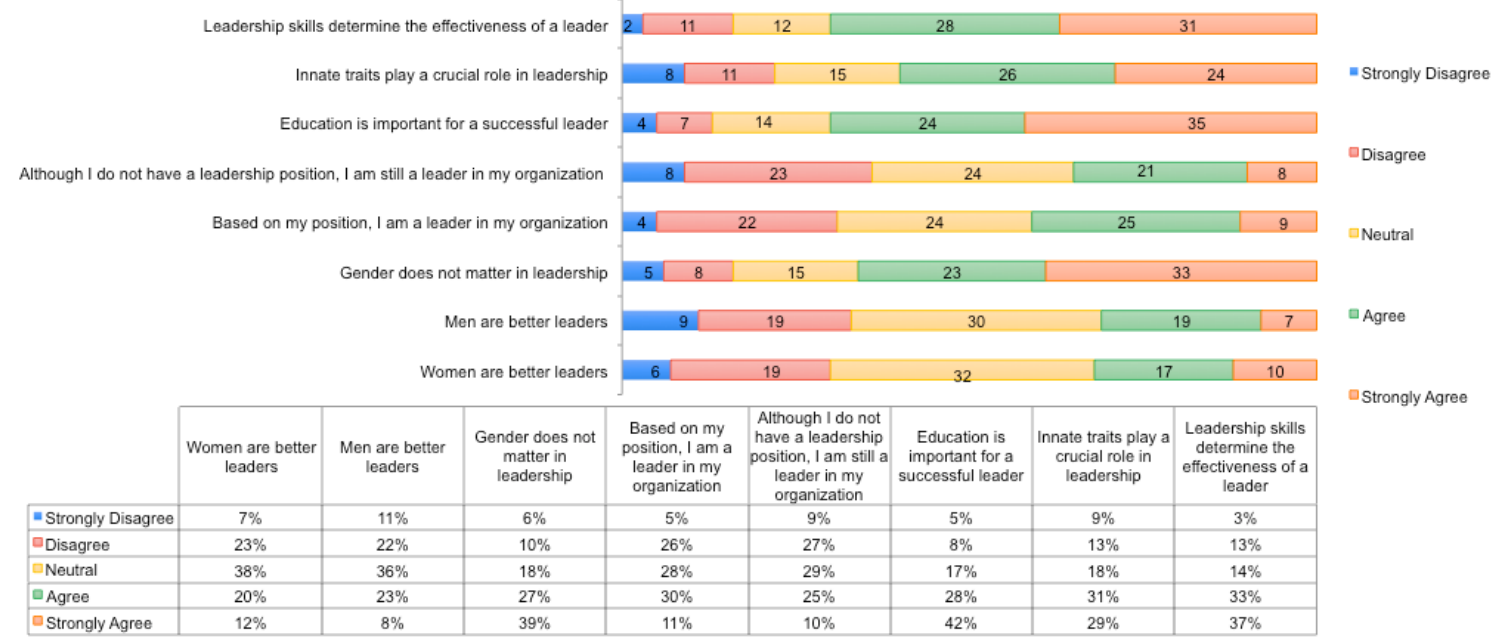

Fig. 3. Statements regarding Respondents Perception of Leaders

Please indicate how strongly you agree or disagree with all the following statements which apply to you by selecting a number 1 - strongly disagree, 2 -disagree, 3- neutral, 4- agree and 5 -strongly agree. $N=84$

The young employees consider that female leaders can be successful if they have appropriate power and relevant positions in their organizations since they need support from the management (Figure 4). Besides, women leaders should possess leadership skills and characteristics, but also proper education. The respondents disagree with the statement that a woman cannot be a good leader, and disagree or strongly disagree with the statement that a woman doesn't need to be a leader. 


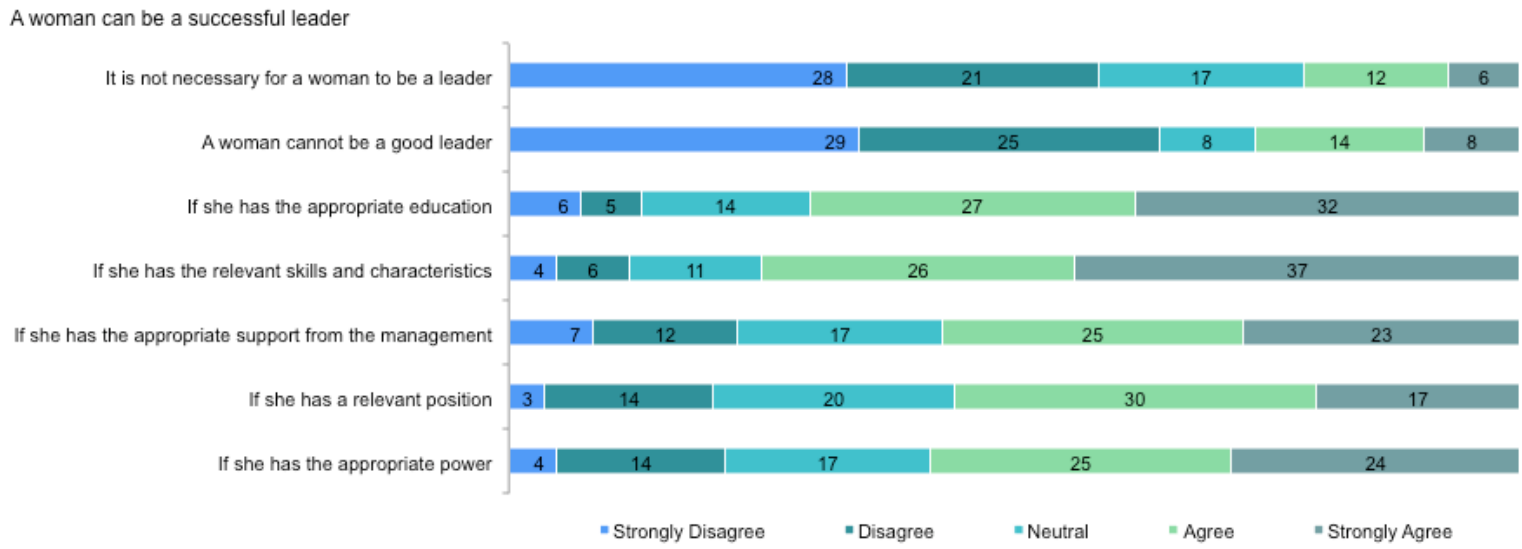

Fig. 4. Statements Regarding Female Leaders $(n=84)$

Please indicate how much you agree or disagree with the following statements

The survey was also interested in the reflection of the young employees concerning male leaders (Figure 5). The vast majority of the respondents disagree that all men are leaders $(n=55)$ and that men do not need to learn leadership $(\mathrm{n}=54)$. On the contrary, they disagree that the strong point of a man is to be a leader $(n=43)$, and that men have more chances to become leaders $(n=42)$. The young employees do not believe that society recognizes only men as leaders in Georgia (strongly disagree $n=14$, and disagree $n=26$ ). However, 24 of them agree and 8 strongly agree that culture helps men to be leaders.

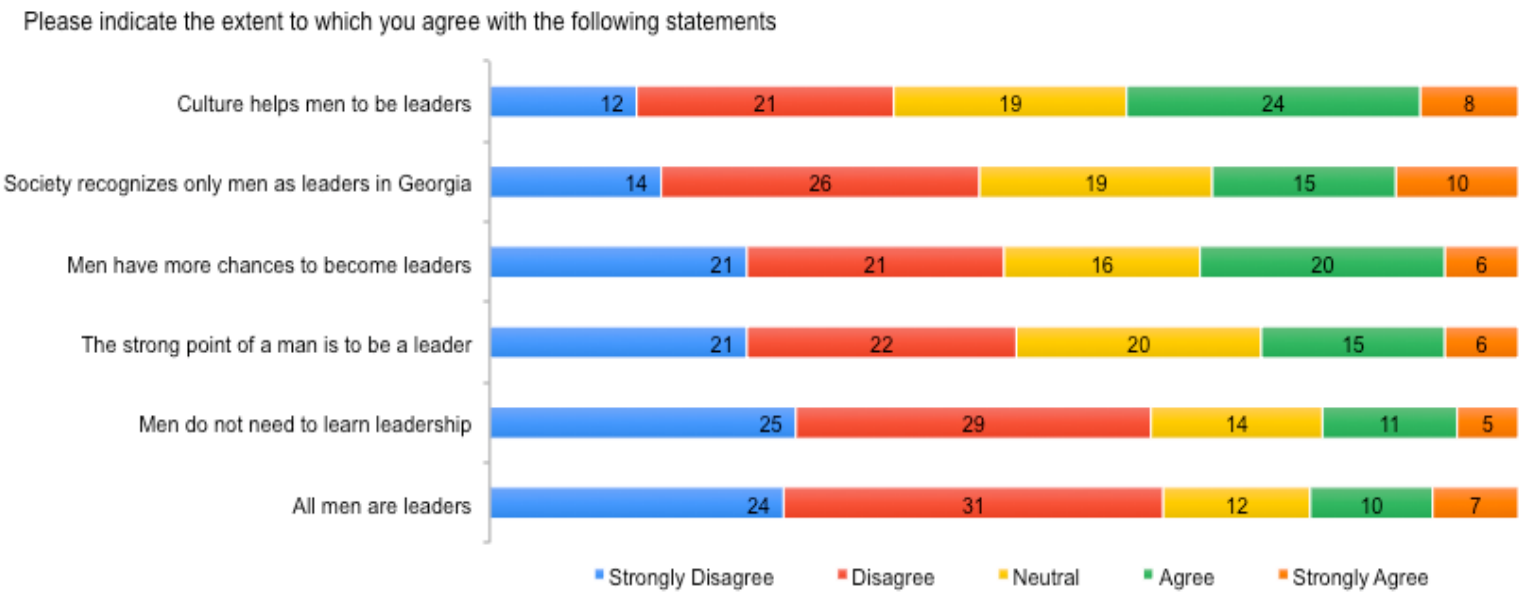

Fig. 5. Statements Regarding Male Leaders ( $n=84)$

Conclusions. The study results emphasize the preferences of young employees towards leaders, which can be used by organizations to develop leadership styles accordingly, and attract and retain employees as a consequence. The conducted research has revealed that young people prefer supportive leaders that are ready to help when employees perform their jobs. Besides, the young employees entering the job market consider leaders' skills and behavior as important and believe that men and women leaders can be equally successful.

Future causal research needs to be carried out to examine the leadership style and behavior of male and female leaders in various organizations with larger samples of employees, which will be analyzed through complex statistical tools.

\section{REFERENCES}

1. Bendell, J., \& Little, R. (2015). Seeking Sustainability Leadership. The Journal of Corporate Citizenship, (60), 13-26. Retrieved April 15, 2021, from http://www.jstor.org/stable/jcorpciti.60.13

2. Chankova, D. \& Vasilev, V. (2020(. Leadership and Deliberative Democracy in the Changing World: Competing Or Reconcilable Paradigms? Perspectives of Law and Public Administration, Societatea de Stiinte Juridice si Administrative (Society of Juridical and Administrative Sciences), 9(2), 209-218. 
3. Diebig, M., Poethke, U., \& Rowold, J. (2017). Leader strain and follower burnout: Exploring the role of transformational leadership behaviour. German Journal of Human Resource Management / Zeitschrift Für Personalforschung, 31(4), 329-348. Retrieved April 15, 2021, from https://www.jstor.org/stable/26905375

4. Donkor, F., \& Sekyere, I. (2020). Importing Complexity Leadership Theory into Bureaucratic Organizations in Non-Western Environments. International Journal of Applied Management Theory and Research, 2(2), 1-18. https://doi.org/10.4018/ijamtr.2020070101

5. Eagly, A. H. (2020, September 8). Once more: The rise of female leaders. American Psychological Association. Retrieved April 11, 2021, from https:/www.apa.org/research/action/female-leaders

6. Förster, C., \& Duchek, S. (2017). What makes leaders resilient? An exploratory interview study. German Journal of Human Resource Management / Zeitschrift Für Personalforschung, 31(4), 281-306. Retrieved April 15, 2021, from https://www.jstor.org/stable/26905373

7. Galli, B. J. (2021). The Relationship and Impact of Communication on Leadership. International Journal of Applied Management Sciences and Engineering, 8(1), 1-11. https://doi.org/10.4018/ijamse.2021010101

8. Kulshreshtha, K., \& Sharma, G. (2021). Understanding e-leadership: Please mind the gap. Technological Forecasting and Social Change, 168, 120750. https://doi.org/10.1016/j.techfore.2021.120750

9. Kusdi. (2020). The Effect of Leadership Style Towards Corporate Culture and the Implementation of Green Management and Its Performance. International Journal of Entrepreneurship and Governance in Cognitive Cities (IJEGCC), 1(1), 31-46. https://doi.org/10.4018/ijegcc.2020010102

10. Leitão, C. F., Gomes, J., Capela dos Santos, D., \& Maia, B. M. (2021). Impact of Leadership on the Relationship Between Innovation and Performance: Portuguese Hotel Sector. International Journal of Tourism and Hospitality Management in the Digital Age (IJTHMDA), 5(2), 29-49. doi:10.4018/IJTHMDA.2021070103

11. Malik, S., Saleem, M., \& Naeem, R. (2016). Effect of Leadership Styles on Organizational Citizenship Behaviour in Employees of Telecom Sector in Pakistan. Pakistan Economic and Social Review, 54(2), 385406. Retrieved April 15, 2021, from https://www.jstor.org/stable/26616714

12. Sajfert, D., Nikolić, M., Vukonjanski, J., Terek, E., \& Vulović, M. (2017). The impact of leaders' ethical behavior on certain individual and organizational effects: The Serbian case. Journal of East European Management Studies, 22(4), 444-483. Retrieved April 15, 2021, from http://www.jstor.org/stable/26407228 